\title{
PARTIDA DE UM REATOR ANAERÓBIO HORIZONTAL PARA TRATAMENTO DE EFLUENTES DO PROCESSAMENTO DOS FRUTOS DO CAFEEIRO
}

\author{
ALISSON C. BORGES ${ }^{1}$, PRISCILA DOS A. PEREIRA ${ }^{2}$, ANTONIO T. DE MATOS ${ }^{3}$
}

RESUMO: O presente estudo teve o objetivo de avaliar a partida e a adaptação de um reator anaeróbio horizontal de leito fixo (RAHLF) no tratamento de águas residuárias do processamento primário dos frutos do cafeeiro (ARC). O reator foi construído com tubos de PVC de 0,2 $\mathrm{m}$ de diâmetro e 3,2 m de comprimento. O sistema foi preenchido com cubos de espuma de poliuretano para imobilização de biomassa ativa. $O$ reator apresentou volume total de $0,1 \mathrm{~m}^{3}$ e volume útil equivalente a $0,04 \mathrm{~m}^{3}$. Em média, houve remoção de $49 \%$ da matéria orgânica, com o reator trabalhando sob carga orgânica volumétrica média de $2,66 \mathrm{~kg} \mathrm{~m}^{-3} \mathrm{~d}^{-1}$, medida como DQO. A suplementação de alcalinidade, somada à inoculação prévia de biomassa, proporcionou partida estável do RAHLF, confirmada pelo consumo de ácidos voláteis e adaptação da microbiota ao resíduo. O sistema apresentou resistência às variações de vazão e de carga orgânica observadas, e os teores de fenol e potássio monitorados não causaram inibição da atividade biológica no RAHLF. O maior controle sobre as variações de carga é fator importante na continuidade dos estudos.

PALAVRAS-CHAVE: biomassa imobilizada, digestão anaeróbia, efluentes agroindustriais, cafeicultura.

\section{START-UP OF AN ANAEROBIC HORIZONTAL-FLOW REACTOR FOR TREATING WASTEWATER FROM A COFFEE FRUITS PROCESSING}

\begin{abstract}
This study aimed to evaluate the start-up and the adaptation of an anaerobic horizontal-flow immobilized biomass (HAIB) reactor in order to treat wastewater from a primary processing of coffee fruits. The reactor was built with PVC tubes of $0.2 \mathrm{~m}$ in diameter and $3.2 \mathrm{~m}$ in length. The system was filled with cubes of polyurethane foam for immobilization of active biomass. The reactor presented a total capacity of $0.1 \mathrm{~m}^{3}$ and reaction volume equal to $0.04 \mathrm{~m}^{3}$. $49 \%$ of organic matter. Removal efficiency was observed, with medium organic volumetric loads equal to $2.66 \mathrm{~kg} \mathrm{~m}^{-3} \mathrm{~d}^{-1}$ (as chemical oxygen demand). The supplementary addition of alkalinity and the previous biomass inoculation provided a stable start-up of the reactor, as confirmed by the reduction of volatile acids and an adaptation of the present microbiology community. The systems showed resistance to changes in flow and in the organic load observed; the levels of phenol and potassium monitored did not cause inhibition of the biological activity. A better control on the changes in load rates is an important topic for the next studies.
\end{abstract}

KEYWORDS: immobilized biomass, anaerobic digestion, agro-industrial effluents, coffee culture.

\section{INTRODUÇÃO}

A cafeicultura moderna é uma atividade importante na economia de diversos países em desenvolvimento, movimentando, em toda sua cadeia, cerca de 91 bilhões de dólares anuais. Para melhorar a qualidade da bebida, os produtores têm usado na fase pós-colheita a remoção da camada externa do fruto por via úmida (lavagem, despolpa e, em alguns casos, a desmucilagem), consumindo de 3 a $5 \mathrm{~m}^{3}$ de água para cada $\mathrm{m}^{3}$ processado (MATOS et al., 2006, 2007).

A água residuária do processamento dos frutos do cafeeiro (ARC) é rica em material orgânico, nutrientes e outros micropoluentes como polifenóis (ácido cafeico e cafeína). Segundo

\footnotetext{
${ }^{1}$ Eng $^{\mathrm{o}}$ Civil, Prof. Adjunto, Departamento de Engenharia Agrícola, UFV, Viçosa - MG, Fone: (0XX31) 3899.1876, borges@ ufv.br

${ }^{2}$ Eng ${ }^{a}$ Agrícola e Ambiental formada pela UFV, Viçosa - MG, priscila.anjos@ig.com.br

${ }^{3}$ Prof. Associado, Departamento de Engenharia Agrícola, UFV, Viçosa - MG, atmatos@ufv.br

Recebido pelo Conselho Editorial em: 29-10-2008

Aprovado pelo Conselho Editorial em: 6-10-2009
}

Eng. Agríc., Jaboticabal, v.29, n.4, p.661-669, out./dez. 2009 
MATOS et al. (2003) e BRUNO \& OLIVEIRA (2008), os valores de matéria orgânica, medidos como demanda bioquímica de oxigênio (DBO), podem variar de $1.500 \mathrm{mg} \mathrm{L}^{-1}$ a $15.000 \mathrm{mg} \mathrm{L}^{-1}$, dependendo do tipo de grão, processamento e opção por reúso de parte do efluente no processamento.

A adoção de sistemas anaeróbios é uma alternativa para o tratamento desse tipo de água residuária, pois essa é uma opção simplificada e de baixo custo, podendo tratar efluentes produzidos de maneira sazonal, como é o caso da ARC. Ademais, grandes produtores mundiais de café, como Brasil e Colômbia, possuem clima quente, o que favorece o mecanismo da digestão anaeróbia.

Pesquisas sobre o tratamento anaeróbio das águas residuárias da indústria da bebida são registradas (FERNANDEZ \& FOSTER, 1993; DINSDALE et al., 1997), mas poucos são os dados sobre investigações com o uso da ARC: citam-se os trabalhos de VIÑAS et al. (1988), que estudaram a tratabilidade desse efluente com o uso de reatores anaeróbios em escala de bancada; de BELLO-MENDONZA \& CASTILLO-RIVERA (1998), que durante 40 dias monitoraram a partida e a adaptação de um reator UASB no tratamento de efluentes de uma planta de processamento primário dos frutos do cafeeiro, e de BRUNO \& OLIVEIRA (2008), que verificaram a viabilidade do tratamento anaeróbio das ARCs em reatores UASB em dois estágios.

A toxicidade de compostos como potássio, fenol e lignina pode ser citada como limitação à atividade metanogênica nesse tipo de tratamento. Nesse sentido, o uso de sistemas com biomassa aderida apresenta-se como alternativa, uma vez que se eliminam as incertezas quanto à formação de grânulos. Ademais, os meios suportes usados podem adsorver parte dos compostos tóxicos presentes na ARC. Dentre as inovações surgidas na última década, cita-se o reator anaeróbio horizontal de leito fixo (RAHLF), que tem sido utilizado no tratamento de efluentes como o fenol (BOLANÕS et al., 2001); formaldeído (OLIVEIRA et al., 2004); chorume (CONTRERA et al., 2006), e BTEX e etanol (GUSMÃO et al., 2006). A espuma de poliuretano é um material que tem sido usado com frequência em RAHLF; como exemplo, cita-se o estudo de AMIN (2004), que verificou que a porosidade do leito foi fator determinante na maior eficiência e na estabilidade do processo, quando comparou sistemas RAHLF preenchidos com espuma e com polietileno.

Com a realização deste trabalho, teve-se o objetivo de avaliar a partida e a adaptação da biomassa em um RAHLF no tratamento das águas residuárias do processamento primário dos frutos do cafeeiro, por meio do monitoramento de variáveis relativas ao desempenho e à estabilidade do sistema.

\section{MATERIAL E MÉTODOS}

O sistema proposto constituiu-se de um reator horizontal construído com tubo de PVC, com diâmetro interno de $0,2 \mathrm{~m}$ e $3,20 \mathrm{~m}$ de comprimento, perfazendo uma relação comprimento/diâmetro (L/D) igual a 16, com capacidade total de $0,1 \mathrm{~m}^{3}$. Na parte superior do reator (nos pontos situados a 0,96 e 2,24 m em relação à entrada), foram perfurados dois orifícios ligados por mangueiras para a captação do biogás, e na lateral do RAHLF, quatro amostradores para coletas intermediárias foram distribuídos uniformemente ao longo do comprimento, com distâncias de $0,64 \mathrm{~m}$ entre si.

Como meio-suporte para a imobilização da biomassa, foram utilizados cubos de espuma de poliuretano de $1,67 \mathrm{~cm}$ de aresta e $23 \mathrm{~kg} \mathrm{~m}^{-3}$ de densidade aparente. O módulo foi preenchido com as matrizes inoculadas com lodo macerado, proveniente de um reator UASB, tratando esgotos domésticos da cidade de Ipatinga-MG.

No procedimento de partida do reator horizontal, utilizou-se de efluente diluído da ARC, proveniente de unidade de beneficiamento de frutos de cafeeiro. $\mathrm{O}$ volume foi armazenado em um tanque de $0,2 \mathrm{~m}^{3}$, dotado de um piezômetro e um dispositivo de Mariotte para monitoramento e controle da vazão afluente. O esquema completo do experimento pode ser visualizado na Figura 1. 


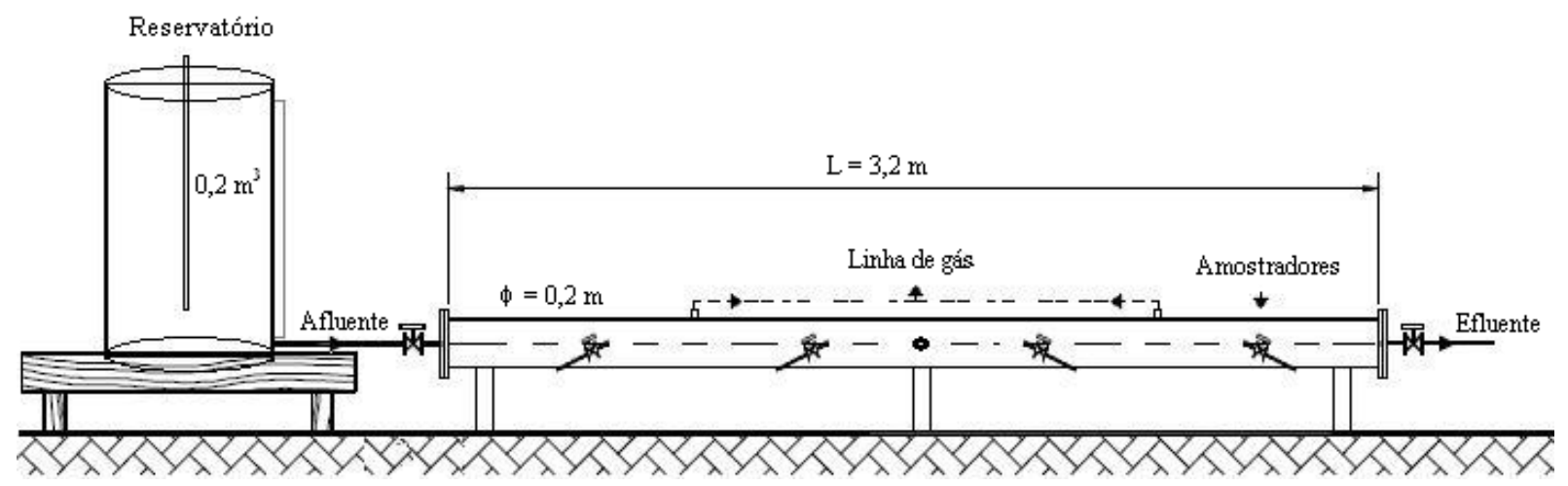

FIGURA 1. Esquema do sistema-piloto para tratamento da ARC (figura sem escala). Scheme of the treatment system for coffee processing effluents (figure without scale).

A biodegradabilidade do substrato afluente foi verificada por meio de estudo do decaimento do conteúdo de matéria orgânica, medida como DBO. O monitoramento do desempenho e da estabilidade da partida do sistema foi feito por meio de análises rotineiras de concentração de matéria orgânica (como DQO), $\mathrm{pH}$, condutividade elétrica, temperatura do líquido e sólidos totais medidos e quantificados, segundo APHA/ AMMA/ WEF (2005). As análises de alcalinidade a bicarbonato e de ácidos voláteis totais foram feitas por análise potenciométrica seguida de titulometria com $\mathrm{H}_{2} \mathrm{SO}_{4}$ e $\mathrm{NaOH}$.

A eficiência de remoção da matéria orgânica, medida como DQO e baseada em amostras não filtradas ( $\square$ ST $)$ e filtradas ( $\square_{\mathrm{SF}}$ ), foi calculada com o uso das eqs. (1) e (2):

$$
\begin{gathered}
\varepsilon_{\mathrm{ST}}=\frac{\mathrm{C}_{\mathrm{Af}}-\mathrm{C}_{\mathrm{ST}}}{\mathrm{C}_{\mathrm{Af}}} \\
\varepsilon_{\mathrm{SF}}=\frac{\mathrm{C}_{\mathrm{Af}}-\mathrm{C}_{\mathrm{SF}}}{\mathrm{C}_{\mathrm{Af}}}
\end{gathered}
$$

em que,

$\mathrm{C}_{\mathrm{Af}}$ - concentração de matéria orgânica no afluente, $\mathrm{mg} \mathrm{L}^{-1}$;

$\mathrm{C}_{\mathrm{ST}}$ - concentração de matéria orgânica não filtrada no efluente, $\mathrm{mg} \mathrm{L}^{-1}$, e

$\mathrm{C}_{\mathrm{SF}}$ - concentração de matéria orgânica filtrada no efluente, $\mathrm{mg} \mathrm{L}^{-1}$.

Atingida a estabilidade na operação, foram realizados ensaios para a obtenção de perfis de concentração ao longo dos amostradores intermediários. Os perfis foram obtidos em dias diferentes (duplicatas) e a amostragem foi do tipo simples. Foram avaliadas as variáveis DQO, sólidos e potássio (APHA/ AWWA/ WEF, 2005), alcalinidade a bicarbonato e ácidos voláteis totais, além de concentrações de fenol, segundo o método da AOAC (2006).

Para a verificação da adaptação da comunidade microbiana ao sistema, foram feitas observações em microscópio comum (Olympus BX60); para tanto, coletaram-se cubos de espuma em pontos distintos no módulo de estudo. Com o fim do período do processamento do café na unidade de beneficiamento, a operação do reator foi suspensa.

\section{RESULTADOS E DISCUSSÃO}

O lodo selecionado apresentou características satisfatórias para ser utilizado como inóculo no sistema: concentração de sólidos voláteis totais (SVT) superior a $40.000 \mathrm{mg} \mathrm{L}^{-1}$ e razão SVT/ST igual a $60 \%$. Após a inoculação em $1,38 \mathrm{~kg}$ de espuma de poliuretano, valores de $0,7 \mathrm{~g} \mathrm{~g}^{-1}$ (SVT por espuma) foram obtidos, resultando em uma quantidade de sólidos voláteis no reator de aproximadamente $1 \mathrm{~kg}$. O volume útil verificado no leito após a inoculação era de $0,04 \mathrm{~m}^{3}$, 
equivalendo, portanto, a $40 \%$ do volume total do RAHLF. Ressalta-se que os valores de tempos de residência e de carga orgânica volumétrica foram calculados com base no volume útil.

O substrato afluente foi caracterizado previamente em laboratório para a análise da biodegradabilidade, da toxicidade e da quantidade de nutrientes. A ARC proveniente da Unidade de Beneficiamento era diluída para uma concentração de matéria orgânica de $1.000 \mathrm{mg} \mathrm{L}^{-1}$ de DQO, e esse substrato apresentou relação DQO:N:P satisfatória, concentração de fenóis de $13 \pm 4 \mathrm{mg} \mathrm{L}^{-1}$ e concentração de potássio equivalente a $72 \pm 23 \mathrm{mg} \mathrm{L}^{-1}$. A relação DBO/DQO da água residuária foi equivalente a aproximadamente $50 \%$.

A água residuária a ser tratada não apresentava capacidade de tamponamento, com valores nulos de alcalinidade a bicarbonato (AB). Após ensaios preliminares (testes em bancada), optou-se pelo uso de carbonato de sódio, numa razão de $0,15 \mathrm{~g} \mathrm{~g}^{-1}$ de DQO, para o fornecimento de alcalinidade e aumento do $\mathrm{pH}$ do afluente.

Após os ensaios prévios, teve-se início a operação do reator com vazão de alimentação de $0,1 \mathrm{~m}^{3} \mathrm{~d}^{-1}$, proporcionando tempo de residência hidráulica (TRH) de $0,40 \mathrm{~d}$ e carga orgânica volumétrica (COV), medida como DQO, de $2,50 \mathrm{~kg} \mathrm{~m}^{-3} \mathrm{~d}^{-1}$. As variações diárias de vazão foram monitoradas durante o estudo: os valores médios de TRH foram de 0,48 $\pm 0,25 \mathrm{~d}$, e as cargas volumétricas aplicadas, equivalentes a 2,66 $\pm 0,44 \mathrm{~kg} \mathrm{~m}^{-3} \mathrm{~d}^{-1}$, com valores máximos de $5,11 \mathrm{~kg} \mathrm{~m}^{-3} \mathrm{~d}^{-1}$, aplicados no $14^{\mathrm{o}}$ dia de operação (Figura 2).

Quanto às variáveis físicas e químicas, os valores médios do monitoramento da partida do reator são apresentados na Tabela 1.

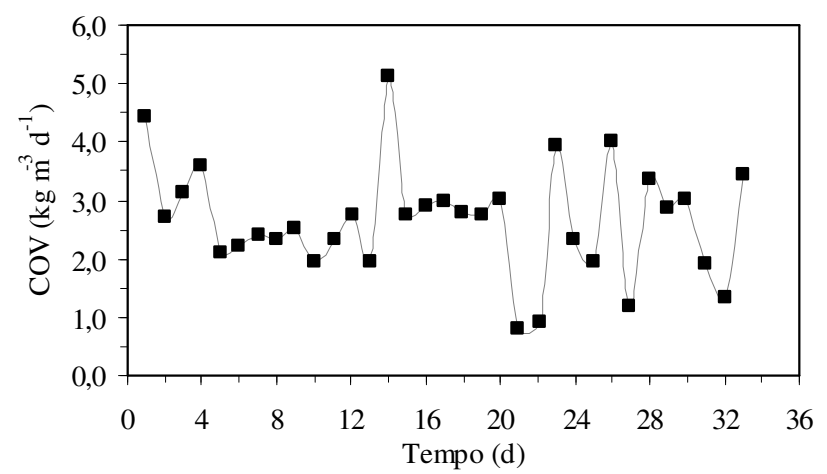

FIGURA 2. Cargas orgânicas volumétricas aplicadas durante a partida do reator. Organic Organic volumetric rates applied in the reactor start-up.

TABELA 1. Variáveis monitoradas no RAHLF durante a partida do sistema. Parameters monitorated in RAHLF start-up.

\begin{tabular}{lcc}
\hline \multicolumn{1}{c}{ Variável $^{(\mathrm{a})}$} & Afluente & Efluente \\
\hline Matéria orgânica $\left(\mathrm{mg} \mathrm{L}^{-1}\right.$ de DQO) & $1.084 \pm 228$ & $692 \pm 223$ (não filtrado) \\
$\mathrm{AB}\left(\mathrm{mg} \mathrm{L}^{-1}\right.$ de CaCO & \\
AVT $\left(\mathrm{mg} \mathrm{L}^{-1}\right.$ de H.Ac.) & $96 \pm 86$ & $132 \pm 89$ \\
pH & $464 \pm 67$ & $376 \pm 128$ \\
$\mathrm{SST}\left(\mathrm{mg} \mathrm{L}^{-1}\right)$ & $6,5 \pm 0,4$ & $6,8 \pm 0,4$ \\
$\mathrm{CE}\left(\mu \mathrm{cm}^{-1}\right)$ & $47 \pm 21$ & $20 \pm 11$ \\
$\mathrm{~T}\left({ }^{\circ} \mathrm{C}\right)$ & $701 \pm 1.084$ & $742 \pm 100$ \\
(a) & $16,7 \pm 1,3$ & $16,21 \pm 1,56$ \\
\hline
\end{tabular}

(a) número de amostragens: no mímimo 14, exceto para concentrações de sólidos (seis análises).

Os valores de eficiência de remoção de substrato $(\varepsilon)$ no reator, obtidos no monitoramento da partida (amostras filtradas e não filtradas), podem ser visualizados na Figura 3. 


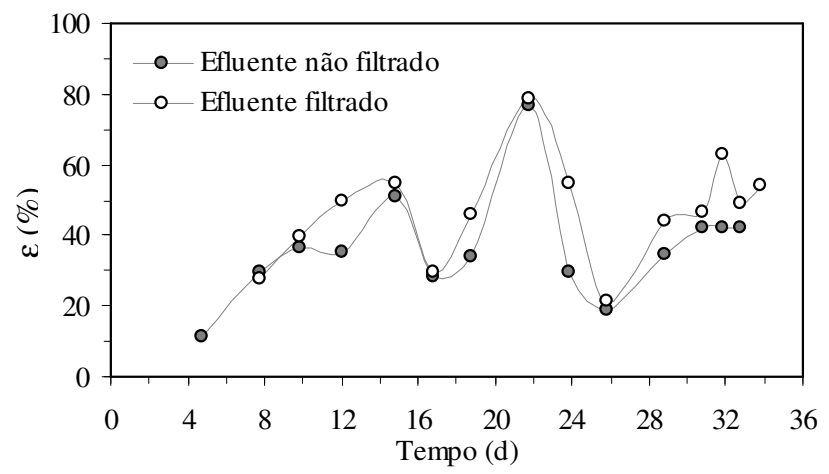

FIGURA 3. Eficiência de remoção de substrato $(\varepsilon)$ no reator. Substrate efficiency removal $(\varepsilon)$ in the reactor.

O sistema apresentou eficiência média de remoção de DQO equivalente a $49 \%$ para amostras filtradas $\left(\varepsilon_{\mathrm{SF}}\right)$. Considerando-se as cargas orgânicas aplicadas (Figura 2), verifica-se que as variações abruptas no carregamento ocorridas no dia 14 (final da segunda semana) e nos dias 21 e 22 (final da terceira semana de operação) influenciaram no desempenho do sistema. Tais variações ocorreram devido a problemas operacionais relacionados à manutenção da vazão, que não foi constante. A remoção diária de matéria orgânica (DQO) medida como vazão mássica foi equivalente a $38 \pm 8 \mathrm{~g} \mathrm{~d}^{-1}$.

Em experimentos de campo, as mudanças nas vazões aplicadas e nas concentrações afluentes são comuns e proporcionam, como consequência, a variação nas COVs aplicadas. BELLOMENDOZA \& CASTILLO-RIVERA (1998) verificaram remoção satisfatória de matéria orgânica (77\%) na partida de um reator UASB de $10,5 \mathrm{~m}^{3}$, quando utilizado no tratamento de água residuária do processamento dos frutos do cafeeiro. No entanto, quando foram aplicadas COVs maiores (2,4 $\mathrm{kg} \mathrm{m}^{-3} \mathrm{~d}^{-1}$ como DQO), houve decréscimo no desempenho do sistema (remoção de $25 \%$ ), com a necessidade de interrupção na operação durante uma semana. Como conclusão desse estudo, que durou 40 dias, os autores recomendam que uma COV de $1,9 \mathrm{~kg} \mathrm{~m}^{-3} \mathrm{~d}^{-1}$ de DQO seria a carga máxima aplicada sem desestabilização do processo.

Ainda em relação a trabalhos em escala plena, resultados modestos são relatados. VIÑAS et al. (1988) monitoraram a partida de um reator UASB e, embora valores consideráveis de remoção tenham sido obtidos, o aumento da COV comprometia a manutenção dos níveis de eficiência. Os mesmos autores monitoraram filtros anaeróbios ascendentes (TRH variando entre 0,4 e 0,8 d) e verificaram a mesma limitação.

Não obstante os problemas ocorridos com as variações sazonais de carga, deve-se ressaltar que as águas residuárias do descascamento/despolpa dos frutos do cafeerio apresentam compostos tóxicos à microbiota anaeróbia, tais como fenóis, além de desbalanço químico (concentrações excessivas de potássio em relação à de outros nutrientes). Dessa maneira, o uso de inóculo com boas propriedades bioquímicas e a adoção do material-suporte escolhido mostraram-se boas opções para a partida do sistema estudado. Ressalta-se que o uso de biomassa aderida elimina as incertezas quanto à granulação e protege o sistema contra variações de carga.

Embora apresentem vantagens, os RAHLFs preenchidos com espuma de poliuretano podem apresentar queda de rendimento com o aumento de escala. Os valores de eficiência obtidos em escala de bancada (COLIN et al., 2007) foram superiores aos obtidos em escala-piloto por LIMA et al. (2005a,b) e CONTRERA et al. (2006). O comprometimento da hidrodinâmica devido à progressiva diminuição do volume útil e a adaptação da biomassa ao resíduo a ser tratado são os fatores citados como responsáveis pela perda de eficiência na operação em escala maior.

Diante do exposto, considera-se que os valores de eficiência obtidos na etapa de partida e na adaptação foram satisfatórios, quando considerados fatores como estabilidade operacional 
verificada, elevadas cargas aplicadas, características particulares do resíduo e limitações de transferência de massa no leito do sistema-piloto.

A estabilidade do sistema, citada anteriormente como fator positivo, foi analisada por meio dos valores de alcalinidade e de ácidos voláteis. Embora a relação alcalinidade intermediária/alcalinidade parcial seja elevada (valores sempre superiores a 0,3), observaram-se geração de alcalinidade a bicarbonato e consumo de ácidos voláteis totais (média de $45 \mathrm{mg} \mathrm{L}^{-1}$ ) durante o estudo, o que indica operação estável do reator (Figura 4). A manutenção do pH na faixa ideal para a digestão anaeróbia (valores médios de 6,5 no afluente e de 7,0 no efluente) corrobora essa observação.

Ao final do experimento, foram coletadas amostras simultâneas nos amostradores intermediários e nos pontos afluente e efluente do sistema. Os perfis obtidos indicam a degradação da matéria orgânica ao longo do comprimento do reator e permitem que observações sobre o comportamento do reator sejam verificadas em relação às variáveis monitoradas $(\mathrm{AB}, \mathrm{AVT}$, fenóis e potássio).

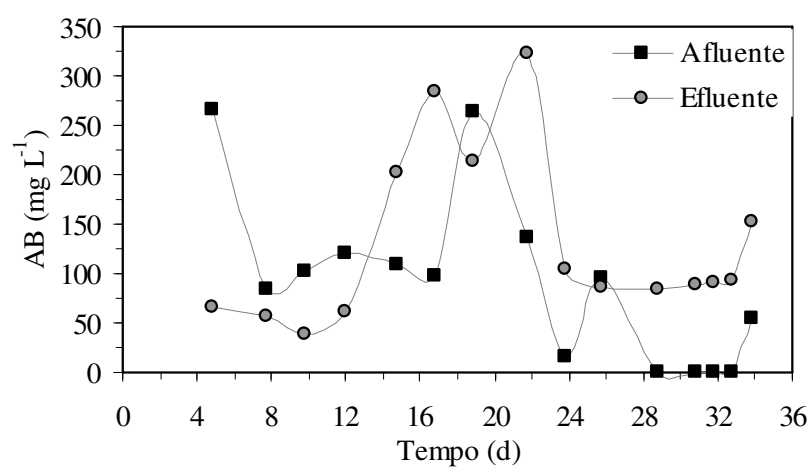

(a)

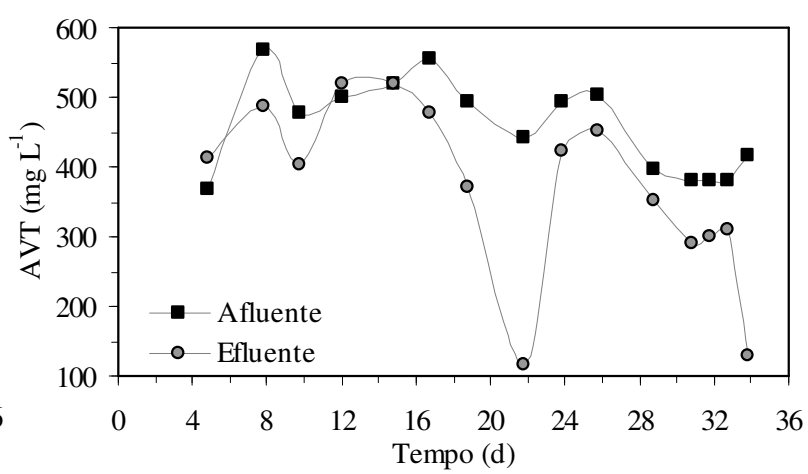

(b)

FIGURA 4. Alcalinidade a bicarbonato (a) e concentrações de ácidos voláteis (b) registradas durante o período de experimentação. Bicarbonate alkalinity (a) and volatile acids concentrations (b) registered in the experimentation.

A Figura 5 contém os dados relativos aos perfis de concentração de matéria orgânica (DQO filtrada) e de ácidos voláteis totais (como ácido acético). Observa-se que a manutenção dos valores de ácidos voláteis totais no interior do módulo deve-se à acetogênese, etapa precursora da formação de metano. A correlação de 0,90 entre os valores obtidos nos perfis de AVT e DQO corroboram tal afirmação. Os ácidos voláteis, que são compostos intermediários na digestão anaeróbia, são responsáveis pelos valores de DQO nos pontos intermediários do RAHLF; com a ocorrência da metanogênese, a DQO devida aos AVTs apresentou-se menor na saída do sistema.

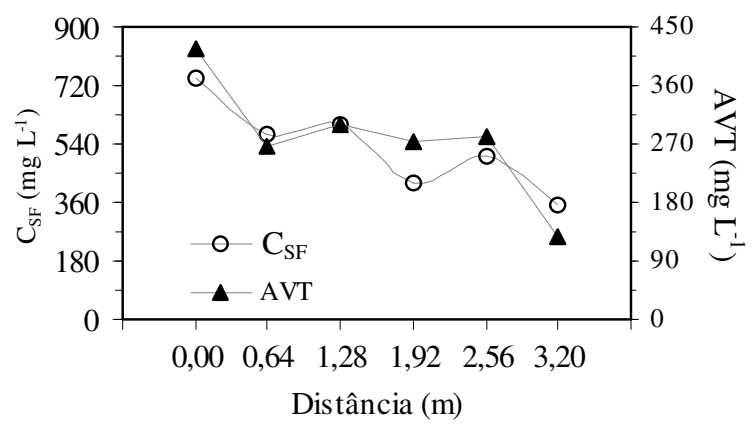

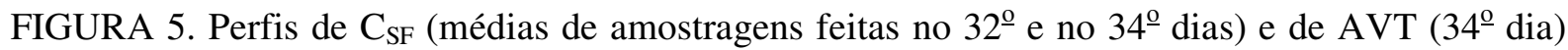
obtidos experimentalmente ao longo do comprimento do reator. $\mathbf{C}_{\mathbf{S F}}$ and TVA profiles obtained in the reactor length. 
Apesar das elevadas concentrações de ácidos, o sistema manteve a sua capacidade-tampão, com manutenção da alcalinidade a bicarbonato e o consequente equilíbrio no pH (Figura 6).

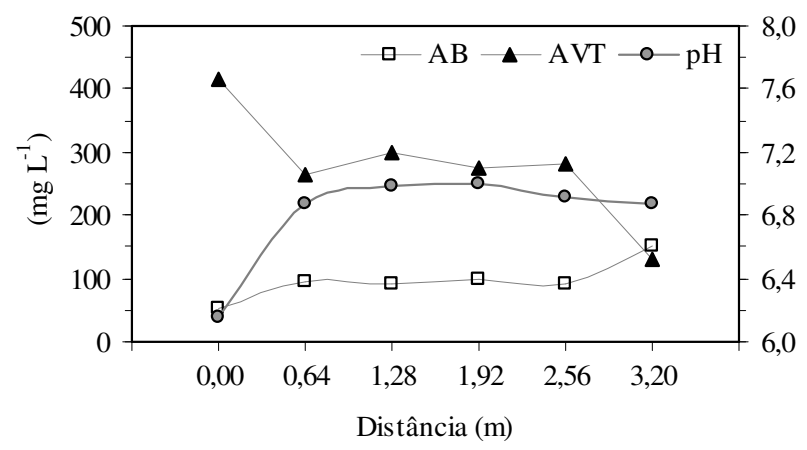

FIGURA 6. Perfis de $\mathrm{AB}$ (medida como $\mathrm{CaCO}_{3}$ ), de AVT (como ácido acético) e de $\mathrm{pH}$ (escala secundária) obtidos experimentalmente ao longo do comprimento do reator no $34^{\circ}$ dia de operação. Alkalinity, TVA and pH profiles obtained in the reactor length.

Os perfis de concentrações de sólidos evidenciaram a diminuição progressiva de quantidades de sólidos dissolvidos, assimilados pela biomassa e convertidos em lodo e metano; contudo, devido à rápida partida do sistema, não se observou obstrução do volume útil com polímeros extracelulares tampouco formação de lodo de excesso. Em relação às concentrações de fenóis e potássio, foi realizado um levantamento em perfil de concentrações dessas variáveis (Figura 7). Verifica-se que, depois do período de partida, não houve remoção significativa desses compostos no interior do reator.

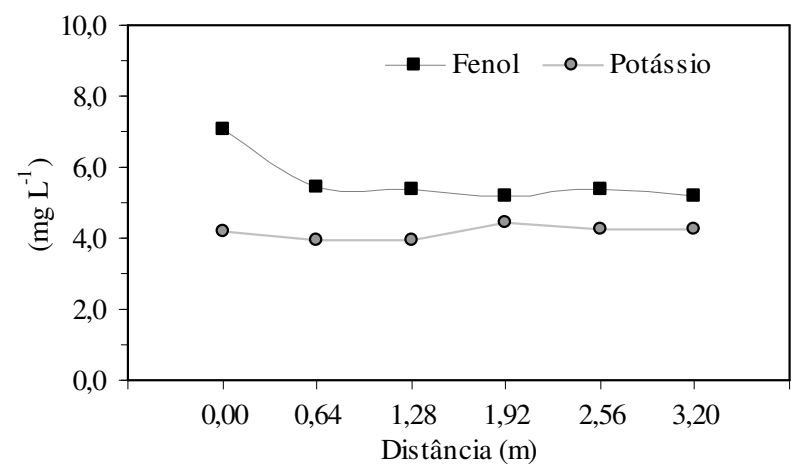

FIGURA 7. Perfis de concentrações de fenol e de potássio no interior do reator no $34^{0}$ dia de operação. Phenol and potassium profiles in the rector length.

O desbalanço químico, repercutindo desfavoravelmente na qualidade nutricional em virtude da concentração excessiva de potássio no afluente, pode inibir etapas metabólicas da digestão anaeróbia. A adição de cálcio pode minimizar essa inibição, por meio de reações de antagonismo (FERNANDEZ \& FOSTER, 1993; DAOMING \& FOSTER, 1993). No entanto, neste experimento, não foram observados efeitos diretos das concentrações de potássio no desempenho do reator.

As análises microbiológicas realizadas no final do experimento permitiram que a presença dos grupos microbianos no biofilme formado no meio-suporte fosse avaliada. A ocorrência de múltiplas morfologias bacterianas (víbrios, cocos, bacilos, células semelhantes a arqueias metanogênicas) indicou o equilíbrio entre os microrganismos dentro do consórcio responsável pela digestão anaeróbia. Não foram observadas variações na diversidade microbiana para as amostragens feitas em diferentes pontos do sistema, o que é um indicativo de que não houve estratificação em relação aos tipos de microrganismos e substratos intermediários ao longo do comprimento do reator em estudo. Com base nas análises microbiológicas, verificou-se que a espuma de poliuretano se 
mostrou eficaz como suporte para a formação do biofilme bacteriano adaptado ao tratamento da ARC.

\section{CONCLUSÕES}

Com base nos resultados obtidos, verificou-se a viabilidade do uso do reator anaeróbio horizontal de leito fixo no tratamento das águas residuárias do pré-processamento dos frutos do cafeeiro. O RAHLF removeu $38 \mathrm{~g} \mathrm{~d}^{-1}$ de DQO a uma COV média de 2,66 $\mathrm{kg} \mathrm{m}^{-3} \mathrm{~d}^{-1}$, o que equivale à produção teórica de metano equivalente a $13,3 \mathrm{~L} \mathrm{~d}^{-1}$.

A suplementação da alcalinidade com carbonato de sódio mostrou-se eficaz na medida em que se verificou estabilidade operacional na partida do sistema. Contudo, há de se ressaltar que, em caso de aplicação do efluente tratado para fertirrigação de culturas, o uso desse agente alcalinizante torna-se restrito, dado o potencial dispersante do sódio. A espuma de poliuretano mostrou-se eficaz na formação do biofilme fixo com valores de $0,7 \mathrm{~g} \mathrm{~g}^{-1}$ (SVT por espuma).

A estratégia de partida adotada mostrou-se eficaz; análises microscópicas permitiram a observação de diversidade microbiana no biofilme, o que sugere a satisfatória adaptação da biomassa ao resíduo em tratamento.

Além dos estudos dos aspectos fundamentais do processo realizados em laboratório, sugere-se a continuidade de experimentos sobre a tratabilidade desse resíduo em escala-piloto. $O$ uso da água residuária por tempo maior que o período de processamento dos frutos do cafeeiro e o maior controle sobre as variações de concentração e vazão nas unidades de beneficiamento apresentam-se como fatores importantes a serem considerados no futuro.

\section{REFERÊNCIAS}

AOAC. Official methods of AOAC International. 16.ed. Arlington, 2006. 2005 p.

APHA/ AWWA/ WEF. Standard methods for the examination of water and wastewater. $21^{\text {th }}$ ed. Washington, 2005. $1.268 \mathrm{p}$.

AMIN, M.A. Performance evaluation of three anaerobic bioreactors: ASBR, HAIS, and UASB. 2004. 158 f. (Doutorado) Isfahan University of Medical Sciences and Health Services, Isfaban, 2004.

BELLO-MENDOZA, R.; CASTILLO-RIVERA, M.F. Start-up of an anaerobic hybrid (UASB/filter) reactor treating wastewater from a coffee processing plant. Anaerobe, Londres, v.4, n.5, p.219-225, 1998.

BOLAÑOS, R.M.L.; VARESCHE, M.B.A.; ZAIAT, M.; FORESTI, E. Phenol degradation in horizontal-flow anaerobic immobilized biomass (HAIB) reactor under mesophilic conditions. Water Science and Technology, Londres, v.44, n.4, p.167-174, 2001.

BRUNO, M.; OLIVEIRA, R.A. Tratamento anaeróbio de águas residuárias do beneficiamento de café por via úmida em reatores UASB em dois estágios. Engenharia Agrícola, Jaboticabal, v.28, n.2, p.364-377, 2008.

COLIN, X.; FARINET, J.L.; ROJAS, O.; ALAZARD, D. Anaerobic treatment of cassava starch extraction wastewater using a horizontal flow filter with bamboo as support. Bioresource Technology, Oxford, v.98, n.8, p.1.602-1.607, 2007.

CONTRERA, R.C.; ZAIAT, M.; SCHALCH, V. Tratamento biológico de lixiviados de aterros sanitários utilizando reator anaeróbio horizontal de leito fixo (RAHLF). Minerva, São Carlos, v.2, n.1, p.65-74, 2006.

DAOMING, S.; FORSTER, C.F. An examination of the start-up of a thermophilic upflow sludge blanket reactor treating a synthetic coffee waste. Environmental Technology, Londres, v.14, n.10, p.965-972, 1993. 
DINSDALE, R.M.; HAWKES, F.R.; HAWKESI, D.L. Comparison of mesophilic and thermophilic upflow anaerobic sludge blanket reactors treating instant coffee production wastewater. Water Research, Oxford, v.31, n.1, p.163-169, 1997.

FERNANDEZ, N.; FORSTER, C.F. A study of the operation of mesophilic and thermophilic anaerobic filters treating a synthetic coffee waste. Bioresource Technology, Oxford, v.45, n.3, p.223-227, 1993.

GUSMÃO, V.R.; MARTINS, T.H.; CHINALIA, F.A.; SAKAMOTO, I.K.; THIEMANN, O.H.; VARESCHE, M.B.A. BTEX and ethanol removal in horizontal-flow anaerobic immobilized biomass reactor, under denitrifying condition. Process Biochemistry, Oxford, v.41, n.6, p.1.3911.400, 2006.

LIMA, C.A.A.; RIBEIRO, R.; FORESTI, E.; ZAIAT, M. Morphological study of biomass during the start-up period of a fixed-bed anaerobic reactor treating domestic sewage. Brazilian Archives of Biology and Technology, Curitiba, v.48, n.5, p.841-849, 2005 a.

LIMA, C.A.A.; FORESTI, E.; ZAIAT, M. Considerações sobre entupimentos em reator anaeróbio horizontal de leito fixo (RAHLF) tratando esgoto sanitário. In: CONGRESSO BRASILEIRO DE ENGENHARIA SANITÁRIA E AMBIENTAL, 23., 2005, Campo Grande. Anais... Campo Grande: ABES, 2005b. 1 CD-ROM.

MATOS, A.T.; BACHETTI, A.P.; PEREIRA, O.G.; SOARES, A.A.; LO MÔNACO, P.A. Produtividade de forrageiras utilizadas em rampas de tratamento de águas residuárias da lavagem e despolpa de frutos do cafeeiro. Revista Brasileira de Engenharia Agrícola e Ambiental, Campina Grande, v.7, n.1, p.154-158, 2003.

MATOS, A.T.; MAGALHÃES, M.A.; FUKUNAGA, D.C. Remoção de sólidos em suspensão na água residuária da despolpa de frutos do cafeeiro em filtros constituídos por pergaminho de grãos de café submetido a compressões. Engenharia Agrícola, Jaboticabal, v.26, n.2, p.610-616, 2006.

MATOS, A.T.; CABANELLAS, C.F.G.; CECON, P.R.; BRASIL, M.S.; MUDADO, C.S. Efeito da concentração de coagulantes e do $\mathrm{pH}$ da solução na turbidez da água, em recirculação, utilizada no processamento dos frutos do cafeeiro. Engenharia Agrícola, Jaboticabal, v.27, n.2, p.544-551, 2007.

OLIVEIRA, S.V.W.B.; MORAES, E.M.; ADORNO, M.A.T.; VARESCHE, M.B.A.; FORESTI, E.; ZAIAT, M. Formaldehyde degradation in an anaerobic packed-bed bioreactor. Water Research, Oxford, v.38, n.7, p.1.685-1.694, 2004.

VIÑAS, M.; ESPINOSA, M.C.; COHEN, M.E.; LOPEZ, C.; ALVAREZ, J.; GUERRA, R.M. Anaerobic treatment of coffee waste water using UASB reactor. In: INTERNATIONAL SYMPOSIUM ON ANAEROBIC DIGESTION, 5., 1988, Bolonha. Proceedings... Bolonha: IWA, 1988. p.607. 